\title{
Chronic bronchitis in Aboriginal people-prevalence and associated factors
}

\section{S. Konrad, MSc (1); A. Hossain, MSc (1); A. Senthilselvan, PhD (2); J. A. Dosman, MD (3); P. Pahwa, PhD (1, 3)}

This article has been peer reviewed.

\begin{abstract}
Introduction: Knowledge about chronic bronchitis (CB) among Aboriginal people in Canada is limited. The aim of this study was to determine the prevalence of CB and its associated factors among Aboriginal people aged 15 years plus.
\end{abstract}

Methods: Logistic regression analysis was used on data from the cross-sectional 2006 Aboriginal Peoples Survey to determine risk factors associated with CB.

Results: CB prevalence was 6.6\% among First Nations, 6.2\% among Métis and 2.4\% among Inuit. Prevalence was higher among females than males $(7.2 \%$ versus $5.0 \%)$. Individuals with $\mathrm{CB}$ were more likely to be older, living at a lower income, with a lower educational attainment and residing in rural areas. Smoking status and body mass index were also significantly associated with $\mathrm{CB}$, but their effect differed by sex. Obesity was particularly significantly associated with $\mathrm{CB}$ among females compared with males, and current smoking and non-smoking status was significantly associated with $\mathrm{CB}$ among females but not males.

Conclusion: These findings identify factors associated with $\mathrm{CB}$ among Aboriginal people. As such, they may represent potentially preventable risk factors that can inform health promotion and disease prevention practices.

Keywords: chronic bronchitis, Aboriginal people, Aboriginal Peoples Survey

\section{Introduction}

The health of Aboriginal people-First Nations, Metis and Inuit-is notably poorer than that of the general Canadian population, ${ }^{1}$ a trend also observed in their respiratory health. ${ }^{2}$ Approximately $15 \%$ of Aboriginal people have been diagnosed with at least one of four respiratory diseases (asthma, chronic bronchitis [CB], emphysema and chronic obstructive pulmonary disorder [COPD]) compared to $10 \%$ for non-Aboriginal people in Canada, according to the 2005 Canadian Community Health Survey (CCHS). ${ }^{3}$ Agestandardized hospital separation rates in western Canada for Aboriginal people for all respiratory diseases in 2000 were 3040 per 100000 population compared with 920 per 100000 population in their nonAboriginal counterparts. ${ }^{4}$

CB is one such respiratory disease defined as "cough productive of sputum for at least three months of the year for at least two years." 5 CB is a significant cause of morbidity and an underlying condition for the development of COPD. ${ }^{6}$

Our knowledge of $\mathrm{CB}$ and its associated factors in Canadian Aboriginal people is limited. The 2002/03 First Nations Regional Longitudinal Health Survey found age-standardized prevalence of self-reported physician-diagnosed $\mathrm{CB}$ to be $3.7 \%$ in First Nations living onreserve; $^{7}$ the prevalence in Aboriginal people living off-reserve is $4.9 \%$, according to the $2005 \mathrm{CCHS}^{3}$ Both of these rates are higher than the prevalence of $2.4 \%$ found in the non-Aboriginal Canadian population, according to the $2005 \mathrm{CCHS}^{3}$

The prevalence of CB in Aboriginal people may be high due to the high prevalence of various risk factors. Smoking, low family income, poor schooling and inadequate housing, which have been significantly associated with the prevalence and incidence of $\mathrm{CB},{ }^{8-10}$ are more prevalent among Aboriginal people. According to the 2002/03 First Nations Regional Longitudinal Health Survey, roughly 59\% of First Nations self-reported currently smoking, with smoking rates for onreserve First Nations slightly higher than for those living off-reserve. ${ }^{7}$ Smoking rates among Inuit have been reported to be as high as $70 \%{ }^{11}$

In 2005, Aboriginal people aged 25 to 54 years had a much lower median total individual income (\$22 000) compared with their non-Aboriginal counterparts (\$33 000)..$^{12}$ Of those aged 25 to 64 years, $44 \%$ of Aboriginal people compared with $60 \%$ of the general population had completed some post-secondary schooling. ${ }^{13}$ Lower education is often associated with lower socio-economic status, which may correlate with lower income and worse housing conditions. In 2006, Aboriginal people were almost four times as likely to live in crowded homes, and three times as likely to live in a dwelling in need of major repairs than non-Aboriginal people. ${ }^{14}$ Poor

Author references:

1. Department of Community Health and Epidemiology, University of Saskatchewan, Saskatoon, Saskatchewan, Canada

2. Department of Public Health Sciences, School of Public Health, University of Alberta, Edmonton, Alberta, Canada

3. Canadian Centre for Health and Safety in Agriculture, University of Saskatchewan, Saskatoon, Saskatchewan, Canada

Correspondence: Punam Pahwa, Canadian Centre for Health and Safety in Agriculture, University of Saskatchewan, 103 Hospital Drive, Saskatoon, SK S7N 0W8; Tel.: 306-966-7944;

Fax: 306-966-7920; Email: pup165@mail.usask.ca 
housing conditions are often associated with damp and mould, which may lead to adverse respiratory outcomes. ${ }^{2}$

We carried out a descriptive study to assess the relationship between demographic, environmental and population characteristics and CB. To date, the determinants of $\mathrm{CB}$ among Aboriginal people in Canada have not been well established. Thus, the objective of this study was to confirm the prevalence (crude and adjusted) of $\mathrm{CB}$ and determine its associated factors in off-reserve Canadian Aboriginal people aged 15 years and older.

\section{Methods}

\section{Study population and data source}

The Aboriginal Peoples Survey (APS) 2006 is a national cross-sectional survey conducted from October 2006 through March 2007 by Statistics Canada in partnership with Aboriginal organizations. ${ }^{15}$ This is the third time that Statistics Canada has administered the APS, the first being in 1991 and the second in 2001. The target population of this survey was off-reserve First Nations, Métis and Inuit people living in urban, rural and northern locations throughout Canada. A multi-stage sampling design was used to select and collect data from all the provinces. Details of this sampling design can be found elsewhere. ${ }^{15}$ Briefly, a target sample was created based on responses to four screening questions in the 2006 Census long form that indicated that the respondents had Aboriginal ancestors and/or identified as North American Indian and/or Métis and/or Inuit and/or had treaty or registered Indian status and/or had Indian Band membership. The sample was then divided according to domains of estimation, based on Aboriginal identity, age groups and geographical regions. A random sample was then selected within each domain of estimation. The APS included information on Aboriginal identity and ancestry, education, language, labour activity, income, health, communication technology, mobility, housing and family background. There were a total of 48921 participants, with a response rate of $80.1 \%$. Data were collected via self-
TABLE 1

Characteristics of Aboriginal people ${ }^{\mathrm{a}}$ ( $\geq 15$ years) stratified by self-reported chronic bronchitis, 2006, Canada $(\mathrm{N}=48$ 921)

\begin{tabular}{|c|c|c|c|}
\hline & \multicolumn{2}{|c|}{ Chronic Bronchitis, \% } & \multirow[t]{2}{*}{ OR $(95 \% \mathrm{Cl})$} \\
\hline & Yes & No & \\
\hline \multicolumn{4}{|l|}{ Demographic characteristics } \\
\hline \multicolumn{4}{|l|}{ Ethnicity } \\
\hline North American Indian & 6.57 & 93.43 & 1.00 \\
\hline Métis & 6.19 & 93.81 & $0.93(0.79-1.11)$ \\
\hline Inuit & 2.38 & 97.62 & $0.35(0.25-0.47)$ \\
\hline \multicolumn{4}{|l|}{ Sex } \\
\hline Male & 5.00 & 95.00 & 1.00 \\
\hline Female & 7.20 & 92.80 & $1.47(1.23-1.76)$ \\
\hline \multicolumn{4}{|l|}{ Age, years } \\
\hline $15-19$ & 2.67 & 97.33 & 1.00 \\
\hline $20-24$ & 3.12 & 96.88 & $1.17(0.73-1.86)$ \\
\hline $25-34$ & 3.70 & 96.30 & $1.40(0.95-2.06)$ \\
\hline $35-44$ & 6.12 & 93.88 & $2.38(1.67-3.38)$ \\
\hline $45-54$ & 9.09 & 90.91 & $3.64(2.57-5.17)$ \\
\hline$\geq 55$ & 10.06 & 89.94 & $4.07(2.83-5.86)$ \\
\hline \multicolumn{4}{|l|}{ Marital status } \\
\hline Legally married & 6.85 & 93.15 & 1.00 \\
\hline Never married & 4.28 & 95.72 & $0.61(0.50-0.74)$ \\
\hline Divorced or widowed & 10.59 & 89.41 & $1.61(1.30-2.00)$ \\
\hline \multicolumn{4}{|c|}{ Environmental characteristics } \\
\hline \multicolumn{4}{|c|}{ Number of persons per household } \\
\hline$\geq 5$ & 4.08 & 95.92 & 1.00 \\
\hline $3-4$ & 5.32 & 94.68 & $1.34(1.01-1.71)$ \\
\hline$\leq 2$ & 8.22 & 91.78 & $2.11(1.63-2.72)$ \\
\hline \multicolumn{4}{|l|}{ Location of residence $^{b}$} \\
\hline Urban & 6.61 & 93.39 & 1.00 \\
\hline Rural & 5.19 & 94.81 & $0.77(0.66-0.91)$ \\
\hline \multicolumn{4}{|l|}{ Geographical area } \\
\hline Territories $^{c}$ & 1.85 & 98.15 & 1.00 \\
\hline British Columbia & 4.95 & 95.05 & $2.78(1.94-3.98)$ \\
\hline Prairies $^{\mathrm{d}}$ & 4.96 & 95.04 & $2.78(2.05-3.78)$ \\
\hline Ontario & 9.05 & 90.95 & $5.31(3.82-7.37)$ \\
\hline Quebec & 6.89 & 93.11 & $3.95(2.75-5.66)$ \\
\hline Atlantic $^{e}$ & 7.44 & 92.56 & $4.29(3.08-5.97)$ \\
\hline \multicolumn{4}{|l|}{ Socio-economic status } \\
\hline \multicolumn{4}{|l|}{ Educational attainment } \\
\hline University completed & 3.93 & 96.07 & 1.00 \\
\hline Some university & 6.82 & 93.18 & $1.78(1.31-2.43)$ \\
\hline High school completed & 5.29 & 94.71 & $1.36(0.94-1.98)$ \\
\hline Less than high school & 6.95 & 93.05 & $1.82(1.33-2.49)$ \\
\hline \multicolumn{4}{|l|}{ Yearly income, \$ } \\
\hline$\geq 100000$ & 2.69 & 97.31 & 1.00 \\
\hline $80000-99999$ & 3.88 & 96.12 & $1.46(1.01-2.09)$ \\
\hline $60000-79999$ & 5.71 & 94.29 & $2.19(1.58-3.02)$ \\
\hline
\end{tabular}

Continued on the following page 
TABLE 1 (continued)

Characteristics of Aboriginal people ${ }^{\mathrm{a}}$ ( $\geq 15$ years) stratified by self-reported chronic bronchitis, 2006, Canada ( $\mathrm{N}=48$ 921)

\begin{tabular}{|c|c|c|c|}
\hline & \multicolumn{2}{|c|}{ Chronic Bronchitis, \% } & \multirow[t]{2}{*}{ OR $(95 \% \mathrm{Cl})$} \\
\hline & Yes & No & \\
\hline $40000-59999$ & 6.46 & 93.54 & $2.49(1.83-3.40)$ \\
\hline 20 000-39 999 & 7.08 & 92.92 & $2.75(2.05-3.69)$ \\
\hline$<20000$ & 11.45 & 88.55 & $4.66(3.44-6.33)$ \\
\hline \multicolumn{4}{|c|}{ Lifestyle characteristics } \\
\hline \multicolumn{4}{|l|}{ Smoking status } \\
\hline Never smoked & 3.25 & 96.75 & 1.00 \\
\hline Ex-smoker & 6.27 & 93.73 & $1.99(1.54-2.56)$ \\
\hline Current smoker & 8.32 & 91.68 & $2.70(2.14-3.40)$ \\
\hline \multicolumn{4}{|c|}{ Health-related characteristics } \\
\hline \multicolumn{4}{|c|}{ General health status } \\
\hline Excellent & 2.21 & 97.79 & 1.00 \\
\hline Very good & 3.43 & 96.57 & $1.57(1.13-2.16)$ \\
\hline Good & 6.20 & 93.80 & $2.92(2.16-3.94)$ \\
\hline Fair & 14.36 & 85.64 & $7.41(5.39-10.17)$ \\
\hline Poor & 21.94 & 78.06 & $12.41(8.88-17.35)$ \\
\hline \multicolumn{4}{|l|}{ Diabetes } \\
\hline No & 8.10 & 91.90 & 1.00 \\
\hline Yes & 13.16 & 86.84 & $1.72(1.01-2.96)$ \\
\hline \multicolumn{4}{|l|}{ BMI $\left(\mathrm{kg} / \mathrm{m}^{2}\right)$} \\
\hline$<24.9$ & 6.00 & 94.00 & 1.00 \\
\hline $25.0-29.9$ & 5.51 & 94.49 & $0.91(0.73-1.13)$ \\
\hline$>29.9$ & 7.34 & 92.66 & $1.26(1.02-1.55)$ \\
\hline
\end{tabular}

Abbreviations: $\mathrm{BMI}$, body mass index; $\mathrm{Cl}$, confidence interval; OR, odds ratio.

${ }^{a}$ Based on participants in the APS self-identifying as North American Indian and/or Métis and/or Inuit and/or having treaty or registered Indian status and/or Indian Band membership and/or Aboriginal ancestors.

b Based on Statistics Canada determinations. ${ }^{15}$

c Yukon, Northwest Territories, Nunavut.

d Alberta, Saskatchewan, Manitoba.

e New Brunswick, Prince Edward Island, Nova Scotia, Newfoundland.

administered questionnaires or personal interviews over the phone or in person.

The target populations of this survey were Aboriginal children and youth (6-14 years) and Aboriginal adults ( $\geq 15$ years). Since our study focused on the adult population, we excluded APS participants aged less than 15 years.

The University of Saskatchewan Research Ethics Board approved this research. We obtained permission to access the data from Statistics Canada and conducted all analyses within the Statistics Canada
Research Data Centre at the University of Saskatchewan.

\section{Measures}

The APS included a set of questions designed to investigate survey participants' chronic conditions. The variables used for the analysis are defined below.

\section{Outcome}

In this report, the outcome variable of interest for adults was based on the following question: "Have you been told by a doctor, nurse or other health professional that you have: chronic bronchitis?"15

\section{Factors}

Of interest were demographic, environmental, and health and lifestyle variables (see Table 1). Demographic variables consisted of age, sex, ethnicity and marital status; environmental variables consisted of location of residence, number of persons per household and geographical area. Location of residence, rural or urban, was based on Statistics Canada determinations (minimum population concentrations and population density per square kilometer). Geographical areas were broken down into Territories (Yukon, Northwest Territories, Nunavut), British Columbia, Prairies (Alberta, Saskatchewan, Manitoba), Ontario, Quebec, and Atlantic (New Brunswick, Prince Edward Island, Nova Scotia, Newfoundland and Labrador). Healthrelated variables consisted of self-perceived general health status, smoking status and body mass index (BMI). BMI was introduced as a continuous variable in the multivariate model, and was afterwards categorized for a schematic depiction (Figure 2). Socio-economic status variables consisted of education and income.

\section{Statistical analysis}

We calculated the percentage of participants reporting $\mathrm{CB}$ and associated factors. Weight variables computed by Statistics Canada methodologists used in all analyses ensured that the final estimates were representative of the surveyed population. We used weighted multiple logistic regression modelling based on a maximum likelihood to test the association of $\mathrm{CB}$ risk factors. Balanced repeated replication resampling technique was used to estimate the standard errors of regression coefficients in order to account for clustering inherited in the study design of the cross-sectional complex survey. Statistically significant two-way interactions were examined. The results of the models are presented as odds ratios (OR) along with the $95 \%$ confidence intervals (CIs). Statistical packages SAS version 9.2 (SAS Institute Inc., Cary, NC, US) and 
STATA version 11.0 were used to conduct all analyses.

\section{Results}

Of the adult APS respondents, 50.0\% were First Nations, $45.2 \%$ were Metis and the remaining $4.8 \%$ were Inuit. Due to the small number of Inuit in the dataset, they were excluded from all multivariate analyses.

\section{Crude prevalence of chronic bronchitis}

Table 1 summarizes both the prevalence and odds ratio for $\mathrm{CB}$. The crude prevalence of $\mathrm{CB}$ was $6.6 \%, 6.2 \%$ and $2.4 \%$ among First Nations, Metis and Inuit, respectively (Table 1). Overall prevalence was $6.0 \%$ for off-reserve Aboriginal people. Prevalence was $8.3 \%$ among smokers and $3.3 \%$ among non-smokers. CB was more prevalent among females than males $(5.0 \%$ vs. $7.2 \%$ ) and increased with age, from $2.7 \%$ for those aged 15 to 19 years to $10.1 \%$ for those aged 55 years and older. The prevalence was highest in Ontario, at $9.1 \%$, and the Atlantic region, at $7.4 \%$. Prevalence was also higher in those living at a lower income and with a lower educational attainment.

Those with diabetes had a prevalence of $13.2 \%$, while those without had a prevalence of $8.1 \%$.

\section{Adjusted prevalence of chronic bronchitis}

Table 2 summarizes all the variables that were found to be significant predictors of $\mathrm{CB}$ in the multivariate model.

In the multivariate model, the prevalence of $\mathrm{CB}$ among Métis did not significantly differ from that among First Nations $(\mathrm{OR}=1.05 ; 95 \% \mathrm{CI}=1.00-1.10)$. As expected, older respondents were more likely to report CB compared to those in the youngest age group ( $\geq 55$ years: $\mathrm{OR}=3.06 ; 95 \% \mathrm{CI}=2.73-3.43$ ). Those who had never married or else were divorced or widowed were less likely to report $\mathrm{CB}$ (never married: $\mathrm{OR}=0.72 ; 95 \%$ $\mathrm{CI}=0.68-0.78$; divorced/widowed: $\mathrm{OR}=0.90 ; 95 \% \mathrm{CI}=0.84-0.96)$. Income and educational attainment were inversely associated with $\mathrm{CB}$; participants who had not completed high school had 1.4 (95\% $\mathrm{CI}=1.30-1.57)$ times greater odds of having $\mathrm{CB}$ than those with a university degree, and those with an income of less $\$ 20000$ had $3.4(95 \% \mathrm{CI}=3.1-3.6)$ times greater odds of having $\mathrm{CB}$ than those with an income of $\$ 80000$ or more. Urban residence was also positively associated

TABLE 2

Results of logistic regression of the prevalence of chronic bronchitis in Aboriginal peoples ${ }^{\mathrm{a}}$ ( $\geq 15$ years), 2006, Canada $(N=48921)$

\begin{tabular}{|c|c|c|}
\hline & $\begin{array}{c}\text { Regression estimates }(\hat{\beta}) \\
\hat{\beta} \text { (s.e. }(\hat{\beta}))\end{array}$ & $\mathrm{OR}_{\text {adj }}(95 \% \mathrm{CI})$ \\
\hline \multicolumn{3}{|l|}{ Demographic characteristics } \\
\hline \multicolumn{3}{|l|}{ Ethnicity } \\
\hline First Nation (ref) & - & 1.00 \\
\hline Métis & $0.05(0.02)$ & $1.05(1.00-1.10)$ \\
\hline \multicolumn{3}{|l|}{ Sex } \\
\hline Male (ref) & - & 1.00 \\
\hline Female & $0.53(0.13)$ & $1.71(1.32-2.21)$ \\
\hline \multicolumn{3}{|l|}{ Age, years } \\
\hline $15-19$ (ref) & - & 1.00 \\
\hline $20-24$ & $0.08(0.06)$ & $1.08(0.95-1.23)$ \\
\hline $25-34$ & $0.08(0.06)$ & $1.08(0.96-1.21)$ \\
\hline $35-44$ & $0.65(0.06)$ & $1.92(1.72-2.14)$ \\
\hline $45-54$ & $1.08(0.06)$ & $2.94(2.63-3.29)$ \\
\hline$\geq 55$ & $1.12(0.06)$ & $3.06(2.73-3.43)$ \\
\hline \multicolumn{3}{|l|}{ Marital Status } \\
\hline Legally married (ref) & - & 1.00 \\
\hline Never married & $-0.32(0.03)$ & $0.72(0.68-0.78)$ \\
\hline Divorced/widowed & $-0.11(0.04)$ & $0.90(0.84-0.96)$ \\
\hline \multicolumn{3}{|l|}{ Location of residence $^{b}$} \\
\hline Rural (ref) & - & 1.00 \\
\hline Urban & $0.25(0.02)$ & $1.31(1.25-1.38)$ \\
\hline \multicolumn{3}{|l|}{ Educational attainment } \\
\hline University & - & 1.00 \\
\hline Some university & $0.29(0.04)$ & $1.33(1.22-1.45)$ \\
\hline High school completed & $0.09(0.05)$ & $1.09(0.99-1.21)$ \\
\hline Less than high school & $0.36(0.05)$ & $1.43(1.30-1.57)$ \\
\hline \multicolumn{3}{|l|}{ Income, \$ } \\
\hline$\geq 80000$ (ref) & - & 1.00 \\
\hline $60000-79999$ & $0.66(0.04)$ & $1.94(1.79-2.10)$ \\
\hline $40000-59999$ & $0.66(0.04)$ & $1.93(1.78-2.08)$ \\
\hline 20 000-39999 & $0.76(0.04)$ & $2.14(1.98-2.31)$ \\
\hline$<20000$ & $1.21(0.04)$ & $3.36(3.11-3.63)$ \\
\hline BMI $\left(\mathrm{kg} / \mathrm{m}^{2}\right)$ & $-0.07(0.01)$ & $0.93(0.91-0.95)$ \\
\hline $\mathrm{BMI}^{2}$ & $0.00(0.00)$ & $1.00(1.00-1.00)$ \\
\hline \multicolumn{3}{|l|}{ Smoking status } \\
\hline Never smoked (ref) & - & 1.00 \\
\hline Ex-smoker & $0.78(0.07)$ & $2.19(1.91-2.50)$ \\
\hline Current smoker & $1.18(0.06)$ & $3.24(2.86-3.67)$ \\
\hline
\end{tabular}

Continued on the following page 
TABLE 2 (continued)

Results of logistic regression of the prevalence of chronic bronchitis in Aboriginal peoples ${ }^{\mathrm{a}}$ ( $\geq 15$ years), 2006, Canada $(N=48$ 921)

\begin{tabular}{lll} 
& $\begin{array}{c}\text { Regression estimates }(\hat{\beta}) \\
\hat{\beta}(\text { s.e. }(\hat{\beta}))\end{array}$ & OR $_{\text {adj }}(\mathbf{9 5} \% \mathrm{CI})$ \\
\hline $\begin{array}{l}\text { Interactions } \\
\text { (Sex plus smoking status) } \\
\quad \text { Female plus ex-smoker }\end{array}$ & $-1.01(0.08)$ & $0.36(0.31-0.43)$ \\
$\quad$ Female plus current smoker & $-0.60(0.07)$ & $0.55(0.48-0.63)$ \\
(Sex plus BMI) & $0.01(0.00)$ & $1.01(1.00-1.02)$ \\
$\quad$ Female plus BMI & & \\
\hline
\end{tabular}

Abbreviations: $\mathrm{BMI}$, body mass index; $\mathrm{CI}$, confidence interval; $\mathrm{OR}_{\mathrm{adj}}$, adjusted odds ratio; s.e., standard error.

${ }^{\text {a }}$ Based on participants in the APS self-identifying as North American Indian and/or Métis and/or Inuit and/or having treaty or registered Indian status and/or Indian Band membership and/or Aboriginal ancestors.

b Based on Statistics Canada's determinations. ${ }^{15}$

There were also two significant interactions between sex and smoking status and sex and BMI. Among non-smokers and current smokers, females have a higher probability of $\mathrm{CB}$ than do men, whereas among ex-smokers, the probability of $\mathrm{CB}$ was slightly lower for females than males (Figure 1). In all the three categories of BMI (healthy and underweight, overweight, and obese), the probability of $\mathrm{CB}$ was significantly higher in females than males. However, this difference was notably greater in obese people.

\section{Discussion}

By using a cross-sectional cohort, this study determined the prevalence of $\mathrm{CB}$ and examined the associated factors in Aboriginal adults. We found the prevalence of $\mathrm{CB}$ to be $6.0 \%$ overall, $6.6 \%$ for First Nations, $6.2 \%$ for Metis, and 2.4\% for Inuit. The multivariate analysis showed older age, smoking, obesity, lower educational attainment, lower income, and urban residence to be significantly associated with self-reported physiciandiagnosed CB. Two-way interactions between sex and smoking and between sex and BMI were also observed.

Our analysis found the prevalence of CB to be slightly higher than the $4.9 \%$ found by the 2005 CCHS among off-reserve Aboriginal people and the $2.4 \%$ found among non-Aboriginal people. The CCHS measures self-reported health-providerdiagnosed CB in a way similar to the APS.

FIGURE 1

Error-bar graph showing probability of chronic bronchitis in Aboriginal people ( $\geq 15$ years) by sex and smoking status, 2006, Canada

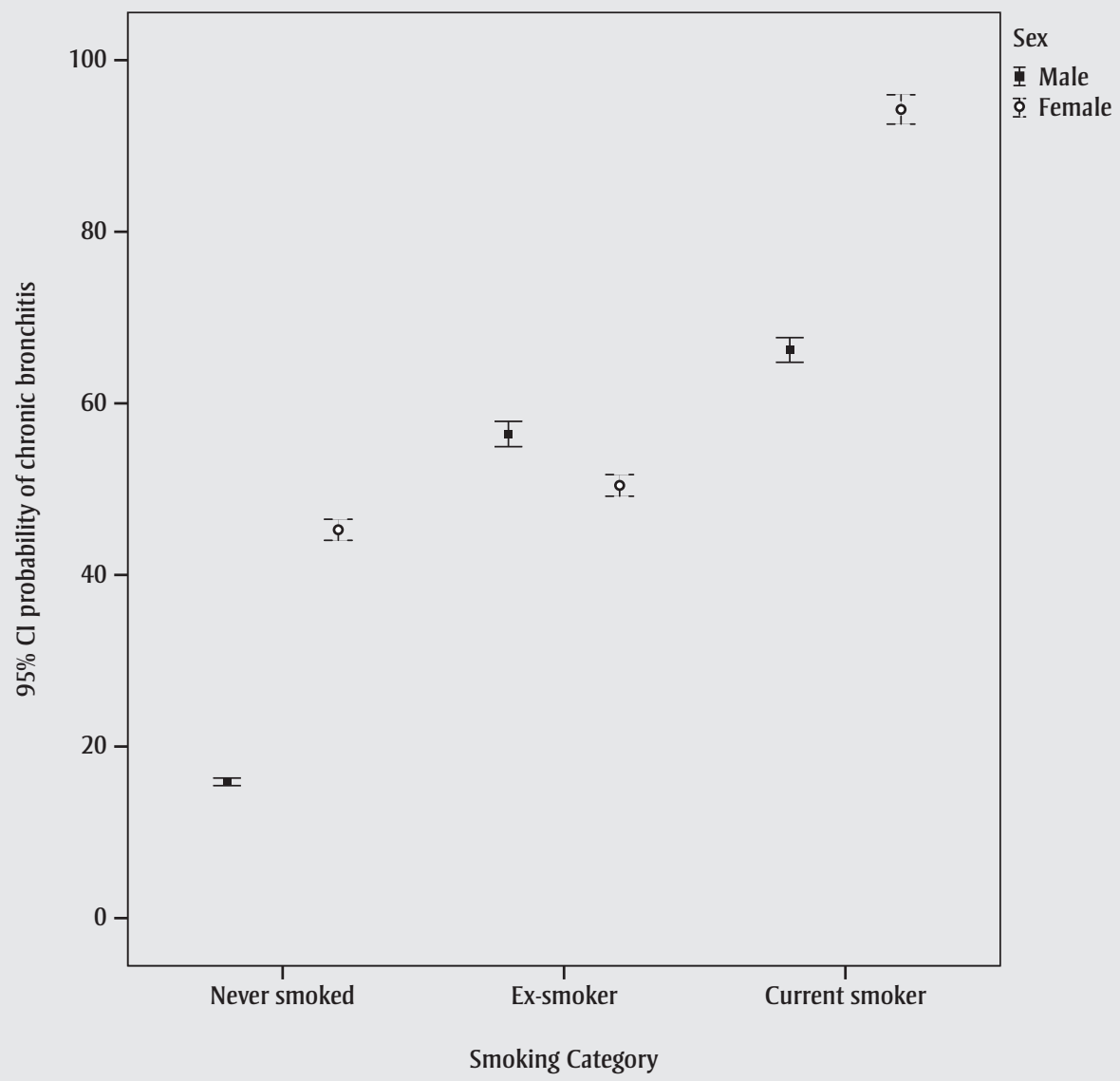


FIGURE 2

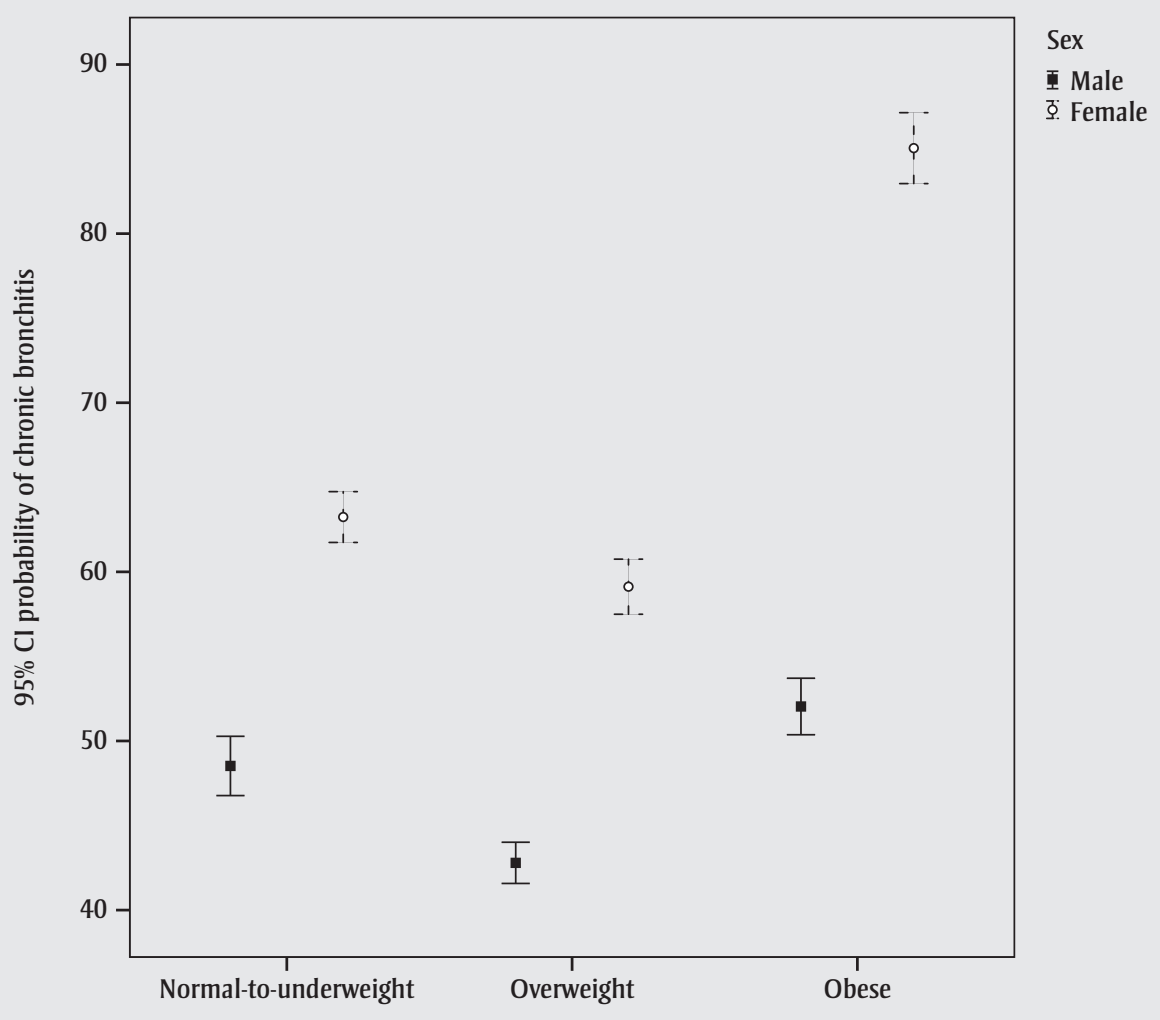

Body Mass Index

The prevalence of CB was particularly low among Inuit compared with First Nations and Métis. Since the rates of smoking were highest in this group, ${ }^{16}$ the low prevalence of $\mathrm{CB}$ may be attributed to geographical barriers in access to care and thus decreased opportunities for a diagnosis. This rationale could also be used to at least partly explain the difference observed between locations of residence, in which urban residents were more likely to self-report physician-diagnosed $\mathrm{CB}$ compared with rural residents.

Supporting our findings of differences by sex in the prevalence of $\mathrm{CB}$, a study from a small Saskatchewan town that focused on a grain-farming population found the prevalence of $\mathrm{CB}$ to be $9.6 \%$ among women and $4.2 \%$ among men. ${ }^{17}$

Numerous other studies also found smoking, income and poor schooling to be independently associated with $\mathrm{CB} .{ }^{5,18,19}$ Smoking is an established and major risk factor for $\mathrm{CB} .{ }^{19}$ Income and education, indicators of socio-economic status, suggest that other variables may be mediating this association. ${ }^{18}$ Low income, for example, limits individual options in healthy living environments and foods, which may, in turn, contribute to obesity. ${ }^{20}$

The link between obesity and chronic respiratory diseases has also become increasingly recognized. In a longitudinal cohort, Guerra et al. ${ }^{21}$ found that patients with $\mathrm{CB}$ were more likely to be obese. In our study, we observed a possible Ushaped risk trend (shown in Figure 1), meaning that both low and high BMI correlated with the disease. Guerra et al. ${ }^{21}$ also observed a similar, albeit nonsignificant, trend. In addition, they observed a temporal relationship; a BMI of $28 \mathrm{~kg} / \mathrm{m}^{2}$ or more increased the risk of receiving a physician-confirmed diagnosis of $\mathrm{CB}(\mathrm{OR}=1.80 ; 95 \% \mathrm{CI}=1.32-2.46)$ two years later. $^{21}$ While their study suggests a causal relationship, more research is needed to elucidate this relationship. Nevertheless, obesity increases the risk of respiratory dysfunction, as indicated by a review of obesity. ${ }^{22}$

\section{Limitations}

There were several limitations to our study. In surveys such as the APS, the measurement of CB lacks clinical accuracy, which could introduce misclassification. ${ }^{23}$ The APS asks a single question about CB, whether respondents have been told by a health care professional that they have CB. Diagnosis of chronic diseases may also be influenced by availability and use of health care services, possibly causing systemic bias. In addition, all answers in this survey are self-reported: self-reporting may under- 
estimate the prevalence of some risk factors, such as weight, smoking status and income. Finally, this survey only collected data on off-reserve First Nations. Based on the 2006 Census, about $40 \%$ of First Nations people live on reserve. ${ }^{14}$ Various statistics do show significant differences between on-reserve and offreserve First Nations, and thus these results may not necessarily be generalizable to all First Nations. In addition, Inuit were removed from the multivariate analysis, further limiting the generalizability of these findings to this population.

\section{Conclusion}

To our knowledge this is the first report that has specifically examined factors associated with $\mathrm{CB}$ among the Aboriginal population. Our research provides a snapshot of $\mathrm{CB}$ and its determinants; nevertheless, further analyses are needed to explore these associations, particularly how low socio-economic status and obesity may be affecting CB. Our study highlights the importance of smoking cessation and reduction in BMI in this population, particularly among females.

In conclusion, this study showed that potentially preventable risk factors (low socio-economic status, obesity and smoking) were significantly associated with $\mathrm{CB}$ after adjusting for possible confounders. Such information may be useful for designing and promoting preventive campaigns specifically for the Aboriginal population.

\section{Acknowledgements}

This study was supported by the Canadian Institute for Health Research pilot project program and the Canadian Centre for Health and Safety in Agriculture.

Conflict of interest: none.

\section{References}

1. MacMillan HL, MacMillan AB, Offord DR, Dingle JL. Aboriginal Health. CMAJ. 1996;155:1569-78.
2. Sin DD, Wells H, Svenson LW, Man SF. Asthma and COPD among Aboriginals in Alberta, Canada. Chest. 2002;121:1841-6.

3. Canadian Community Health Survey (CCHS): detailed information for 2005 (cycle 3.1) [Internet]. Ottawa (ON): Statistics Canada; [modified 2007 Oct 10; cited 2010 Jun 1]. Available from: http:// www23.statcan.gc.ca/imdb/p2SV.pl?Function $=$ getSurvey\&SurvId $=3226 \&$ SurvVer $=0 \&$ InstaId $=15282 \&$ InstaVer $=3 \&$ SDDS $=3226$ \&lang $=e n \& d b=i m d b \& a d m=8 \&$ dis $=2$

4. Health Canada. A statistical profile on the health of First Nations in Canada: health service utilization in Western Canada, 2000 [Internet]. Ottawa (ON): Health Canada; 2009 [cited 2010 Jun 1]. Available from: http://www.hc-sc.gc.ca/fniah-spnia /pubs/aborig-autoch/2009-stats-profil-vol2 /index-eng.php

5. American Thoracic Society. Definitions and classifications of chronic bronchitis, asthma and pulmonary emphysema. Am Rev Respir Dis. 1962;85:762-8.

6. Pelkonen M. Smoking: relationship to chronic bronchitis, chronic obstructive pulmonary disease and mortality. Curr Opin Pulm Med. 2008;14:105-9.

7. First Nations Information Governance Committee. First Nations Regional Longitudinal Health Survey (RHS) 2002/ 03: results for adults, youth and children living in First Nations communities. Ottawa (ON): First Nations Centre; Nov 2005.

8. Minore B, Hill ME, Park J, et al. Understanding respiratory conditions among Ontario's Aboriginal population. Thunder Bay (ON): Centre for Rural and Northern Health Research; 2010.

9. Melia RJ, Chinn S, Rona RJ. Respiratory illness and home environment of ethnic groups. Br Med J. 1988;296:1438-41.

10. Cooreman J, Redon S, Levallois M, Liard R, Perdrizet S. Respiratory history during infancy and childhood, and respiratory conditions in adulthood. Int J Epidemiol. 1990;19:621-7.
11. Wong S. Use and misuse of tobacco among Aboriginal peoples. Paediatr Child Health. 2006;11(10):681-5.

12. Aboriginal statistics at a glance. Income [Internet]. Ottawa (ON): Statistics Canada; 2010 [cited 2010 Jul 22]. Available from: http://www.statcan.gc.ca/pub/89-645-x /2010001/income-revenu-eng.htm

13. Educational portrait of Canada, 2006 Census [Internet]. Ottawa (ON): Statistics Canada; 2008 [cited 2010 Jul 22]. Available from: http://www12.statcan.gc.ca /english/census06/analysis/education/pdf /97-560-XIE2006001.pdf

14. Aboriginal Peoples in Canada in 2006: Inuit, Metis and First Nations, 2006 Census [Internet]. Ottawa (ON): Statistics Canada; 2008 [cited $2010 \mathrm{Jul} 20$ ]. Available at: http:// www12.statcan.ca/census-recensement/2006 /as-sa/97-558/pdf/97-558-XIE2006001.pdf

15. Aboriginal Peoples Survey (APS) [Internet]. Ottawa (ON): Statistics Canada; 2009 [cited 2010 July 22]. Available at: http://www .statcan.gc.ca/imdb-bmdi/3250-eng.htm

16. Hare J. Aboriginal women and healthcare. Friends of women and children in B.C. Report Card, (2004). 3(12).

17. Chen Y, Horne SL, McDuffie HH, Dosman JA. Combined effect of grain farming and smoking on lung function and the prevalence of chronic bronchitis. Int J Epidemiol. 1991;20(2):416-23.

18. Menezes AM, Victora CG, Rigatto M. Prevalence and risk factors for chronic bronchitis in Pelotas, RS, Brazil: a population based study. Thorax. 1994;49:1217-21.

19. Sethi JM, Roschester CL. Smoking and chronic obstructive pulmonary disease. Clin Chest Med. 2000;21:67-86.

20. Obesity in Canada. Determinants and contributing factors [Internet]. Ottawa (ON): Statistics Canada; 2010 [cited 2010 Jul 20]. Available at: http://www.phac-aspc.gc.ca /hp-ps/hl-mvs/oic-oac/determ-eng.php

21. Guerra S, Sherrill DL, Bobadilla A, Martinez FD, Barbee RA. The relation of body mass index to asthma, chronic bronchitis, and emphysema. Chest. 2002;122:1256-63. 
22. Poulain M, Doucet M, Major GC, et al. The effect of obesity on chronic respiratory diseases: pathophysiology and therapeutic strategies. CMAJ. 2006;174(9):1293-9.

23. Bobadilla A, Guerra S, Sherrill D, Barbee R. How accurate is the self-reported diagnosis of chronic bronchitis? Chest. 2002;122: 1234-9. 